\section{INTERSEÇÕES ENTRE OS CAMPOS ESPORTIVO E CIENTÍFICO: A SOCIOLOGIA DO ESPORTE COMO ELEMENTO COMUM (2011- 2018)}

INTERSECTIONS BETWEEN THE SPORTS AND SCIENTIFIC FIELDS: THE SOCIOLOGY OF SPORT AS A COMMON ELEMENT (2011-2018) C?

INTERSECCIONES ENTRE LOS CAMPOS DEPORTIVO Y CIENTÍFICO: LA SOCIOLOGÍA DEL DEPORTE COMO ELEMENTO COMÚN (20112018) C

doi' https://doi.org/10.22456/1982-8918.117275

(iD) André Marsíglia Quaranta* <andrequaranta@gmail.com>

Daniel Minuzzi de Souza* < daniel.souza@ifc.edu.br>

Fernando Marinho Mezzadri*<fmezzadri@uol.com.br>

Wanderley Marchi Júnior* <marchijr@ufpr.br>

*Universidade Federal do Paraná. Curitiba, PR, Brasil.
Resumo: O esporte tem sido objeto de análise em diversas áreas do conhecimento no Brasil. Uma aproximação a partir das Ciências Sociais e Humanas tem possibilitado a exploração de elementos interpretativos singulares que ampliam a compreensão desse complexo fenômeno. Este texto tem como objetivo mapear estudos que versam sobre a Sociologia do Esporte nos programas de pós-graduação brasileiros entre 2011 e 2018, visando contribuir com a sistematização da produção científica desse subcampo. Após levantamento de dissertações e teses, descrevemos as principais características dessas produções, classificando-as em categorias sociológicas para análise do campo esportivo, sendo o futebol hegemonicamente a modalidade mais explorada por pesquisadores de diversas áreas.

Palavras chave: Esportes. Indicadores de produção científica. Sociologia. Revisão.
Recebido em: 30 jul. 2021 Aprovado em: 22 nov. 2021 Publicado em: 30 dez. 2021

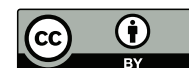

Este é um artigo publicado sob a licença Creative Commons Atribuição 4.0 Internacional (CC BY 4.0).

elSSN: 1982-8918 


\section{INTRODUÇÃO}

A apropriação do fenômeno esportivo pela sociedade se manifesta com variadas possibilidades, seja na própria prática dos diferentes esportes, na utilização desse como um espetáculo a ser comercializado, na sua disseminação através dos meios de comunicação, ou ainda diante da área de inserção discutida neste trabalho, que trata do campo científico por meio da Sociologia do Esporte, conforme pode ser observado em Marchi Júnior (2016).

Souza (2011) destaca que duas tendências teóricas têm orientado os estudos nesse campo: "teoria globalista" e "teoria emocional da ação". A primeira visa organizar um referencial disposto a compreender padrões regulares, tanto culturais como econômicos, numa perspectiva global da sociedade capitalista. A segunda propõe "[...] recuperar as singularidades culturais tornadas regularidades no plano local a partir do método estrutural e comparado" (SOUZA, 2011, p. 34). Para além dessas possibilidades, Souza (2011) sugere o método de análise reflexiva, desenvolvido por Bourdieu, como um caminho para tratar do esporte numa perspectiva analítica sociológica que busque compreender esse complexo fenômeno a partir de sua dinâmica social e polissêmica.

Quando pensamos em Sociologia do Esporte, na contemporaneidade, dois sociólogos despontam por terem se debruçado e produzido sobre o fenômeno esportivo: o francês Pierre Bourdieu e o alemão Norbert Elias, que são referências nas pesquisas no Brasil. Para o presente estudo, interessa-nos abordar as contribuições de Bourdieu, principalmente a partir dos textos "Como é possível ser desportista" (BOURDIEU, 2003a) e "Programa para uma sociologia do esporte" (BOURDIEU, 1990).

Bourdieu compreende o esporte moderno de maneira singular, situando o fenômeno esportivo em um espaço de relações sociais chamado de "campo", e as pessoas que compõem esse espaço social, denominadas de "agentes", são posicionados a partir do acúmulo de "capitais" (social, econômico, cultural, entre outros). Nesse espaço, ocorrem disputas pela hegemonia de alguma prática, conferindo, assim, uma distinção social a partir do poder simbólico nesse representado (MARCHI JÚNIOR, 2017).

Partindo da sociologia reflexiva, ressalta-se que o campo científico é dotado de características peculiares, com uma dinâmica própria pelos agentes que nele atuam. Sendo um espaço social concorrencial, carrega uma característica singular, por ser um espaço de integração social, na qual sua principal forma de interesse se dá a partir de recursos específicos que mobilizam cientistas denominado de capital "científico" (BOURDIEU, 2003b). Esse tipo de recurso se apresenta sob duas formas: na primeira, é chamado de "temporal", com características políticas, associado àqueles agentes que se posicionam em ambientes como laboratórios, departamentos, colegiados etc.; na segunda, denominado de científico "puro" (ou de prestígio), que "[...] repousa quase que exclusivamente sobre o reconhecimento, pouco ou mal objetivado e institucionalizado, do conjunto de pares ou da fração mais consagrada dentre eles" (BOURDIEU, 2003b, p. 35). 
Pensar a interseção entre dois campos de poder - o científico e o esportivo - remete-nos a investigar os agentes e as estruturas que se movimentam para a consolidação da Sociologia do Esporte como um subcampo. Se, por um lado, a Sociologia do Esporte se constitui como um espaço das práticas esportivas diante da posição de cada uma no interior de um sistema (BOURDIEU, 1990), de outro, temos no campo científico o seu espaço, também, de observação e análise dessas mesmas práticas. Configura-se, assim, um espaço possível de diálogo e reflexão que tem suas características próprias lógicas de disputas internas e externas - como a psicologia do esporte, filosofia do esporte, história do esporte, entre outros subcampos possíveis de análise - a partir do posicionamento que ocupam dentro desse universo de práticas científicas ${ }^{1}$. Os desdobramentos das relações estabelecidas entre os agentes e as estruturas da Sociologia do Esporte podem ser estudados por meio das produções acadêmicas.

Estudos anteriores tomaram como objeto a produção científica que relaciona os campos de poder científico e esportivo a partir da Sociologia do Esporte como um subcampo comum possível (FERREIRA, 2009, 2014; MEDEIROS; GODOY, 2009;).

Isso posto, o presente texto tem como objetivo apresentar o mapeamento de estudos que versam sobre a Sociologia do Esporte nos programas de pós-graduação brasileiros entre 2011 e 2018, a fim de contribuir com a sistematização da produção científica desse subcampo.

\section{PERCURSO METODOLÓGICO}

Trata-se de uma pesquisa documental (MARCONI; LAKATOS, 2003), com delineamento exploratório e descritivo, cujas fontes foram dissertações e teses defendidas em programas de pós-graduação brasileiros, depositadas em duas bases de dados brasileiras: a Biblioteca Digital Brasileira de Teses e Dissertações (BDTD) e o Catálogo de Teses e Dissertações da Coordenação de Aperfeiçoamento de Pessoal de Nível Superior (Capes).

Utilizamos como descritor o termo "Sociologia do Esporte" para selecionar estudos defendidos entre 2011 e $2018^{2}$. Excluídas as pesquisas duplicadas nas bases de dados, identificamos 42 dissertações e 12 teses, totalizando 54 estudos $^{3}$, configurando, assim, o corpus de análise do presente trabalho.

Classificamos os trabalhos a partir de categorias sociológicas para análise do campo esportivo sugeridas por Almeida et al. (2016), e adequadas por Marchi Júnior, Almeida e Souza (2019): catarse e violência; corporeidade; dominação ideológica e resistência; diversidade e inclusão social; ecologização; globalização; identidade; racionalização; secularização; socialização e distinção social; outros.

\footnotetext{
1 Souza e Marchi Júnior (2010) destacam que as disputas internas da Sociologia do Esporte no campo acadêmico podem ser observadas por meio das relações entre pesquisadores e instituições científicas, a partir da definição dos objetos de pesquisa, legitimidade teórica e metodológica que permeiam as produções acadêmicas em seu interior. Diante de lógicas externas, os autores destacam como exemplo as influências políticas, porém, com menor impacto em relação às concorrências internas.

2 O recorte temporal deste estudo visou continuar a observação do processo de desenvolvimento da Sociologia do Esporte como subcampo acadêmico-científico no Brasil, levando em consideração a sistematização realizada anteriormente por Ferreira (2014) entre os anos de 1980 e 2010.

3 Dados coletados em 15 de julho de 2019.
} 


\section{RESULTADOS E DISCUSSÃO}

\subsection{ANÁLISE DESCRITIVA DAS DISSERTAÇÕES E TESES}

O levantamento evidencia que os trabalhos acerca da Sociologia do Esporte estão concentrados em duas áreas do conhecimento: Educação Física e Sociologia (Figura 1). Isso equivale a 68\% dos trabalhos defendidos entre 2011 e 2018, ou seja, 37 trabalhos, sendo 26 dissertações (20 na Educação Física e seis na Sociologia) e 11 teses (cinco na Educação Física e seis na Sociologia). As demais áreas nas quais foram encontrados trabalhos são: Interdisciplinar (sete dissertações), Comunicação (três dissertações e uma tese) e Educação (duas dissertações), totalizando 24\% dos trabalhos. Estudos do Lazer, Psicologia, Ciência Política e Políticas Públicas contemplam os demais $8 \%$, cada área com uma dissertação defendida no período mencionado.

Figura 1 - Defesas por área do conhecimento (2011-2018)

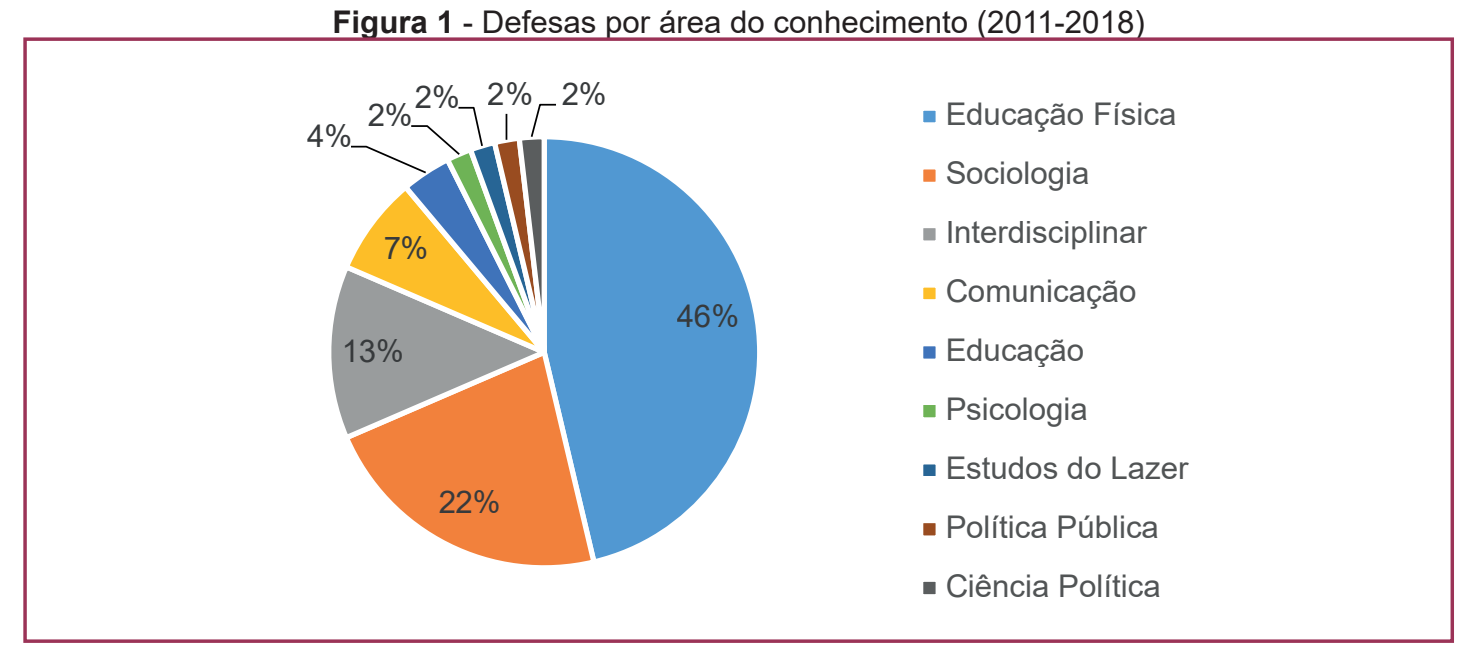

Fonte: dados da pesquisa.

Em relação à evolução do número de trabalhos defendidos, observamos que, em termos quantitativos, há um crescimento não linear: os intervalos entre os anos 2011-2013, 2015-2016 e 2017-2018 apresentam aumento no volume de estudos completados; porém, 2013-2015 e 2016-2017 representam uma queda no número de trabalhos defendidos nas mais diversas áreas (Figura 2). 
Figura 2 - Evolução do número de defesas 2011-2018 (todas as áreas)

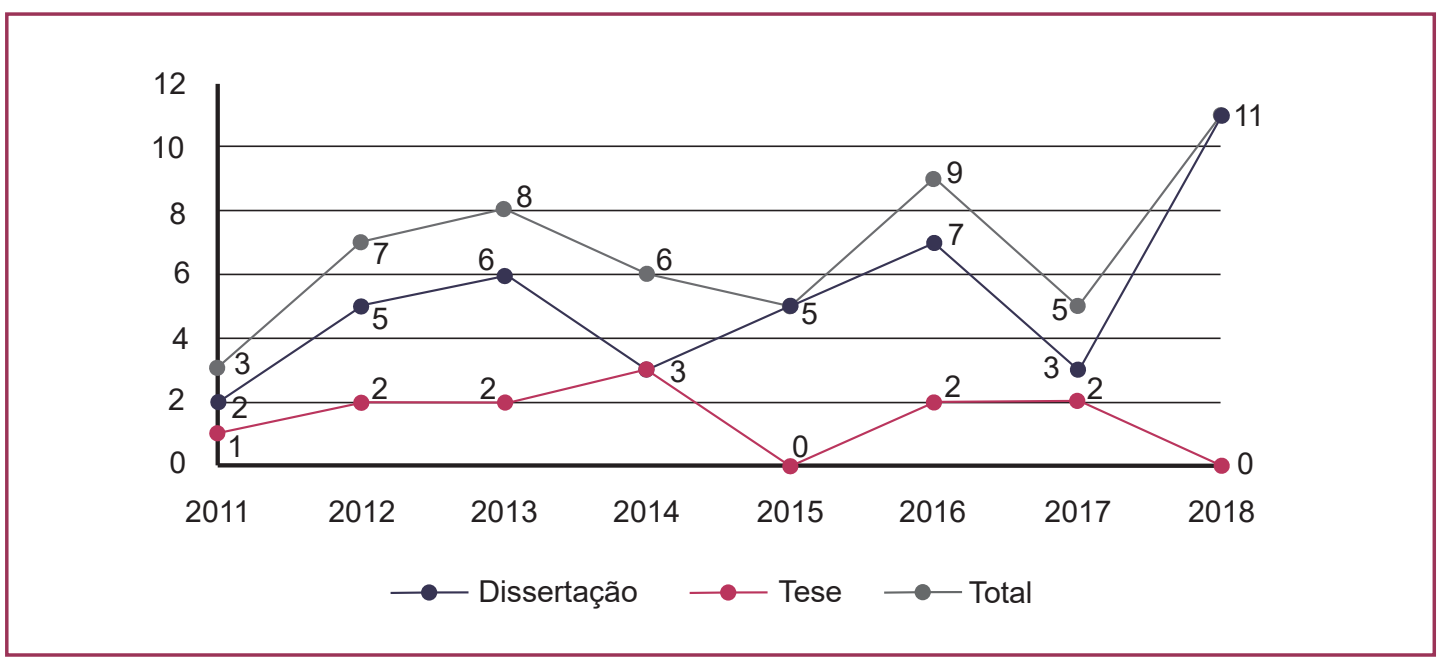

Fonte: dados da pesquisa.

Os programas de pós-graduação que desenvolveram estudos no período analisado se concentram nas regiões Sul e Sudeste, com 26 teses e 22 dissertações. A região Nordeste totalizou quatro estudos e a região Centro-Oeste desenvolveu dois. A região Norte não produziu nenhum trabalho a partir da Sociologia do Esporte (Quadro 1).

Quadro 1 -Teses e dissertações defendidas nos programas de pós-graduação brasileiros (2011-2018)

\begin{tabular}{|l|l|}
\hline Programa de Pós-Graduação em Ciência do Movimento Humano (UFRGS) & 9 \\
\hline Programa de Pós-Graduação em Educação Física (UFPR) & 8 \\
\hline Programa de Pós-Graduação em Sociologia (UFPR) & 5 \\
\hline Programa de Pós-Graduação em Mudança Social e Participação Política (USP) & 4 \\
\hline Programa de Pós-Graduação Associado em Educação Física (UEL-UEM) & 3 \\
\hline Programa de Pós-Graduação em Estudos de Cultura Contemporânea (UFMT) & 2 \\
\hline Programa de Pós-Graduação em Educação (USP-RP) & 2 \\
\hline Programa de Pós-Graduação em Comunicação (Unesp) & 2 \\
\hline Programa de Pós-Graduação em Sociologia (UFC) & 2 \\
\hline
\end{tabular}

Fonte: dados da pesquisa.

Observação: programas com mais de um trabalho defendido.

Até o ano de 2010, de acordo com Ferreira (2014), havia uma hegemonia de trabalhos defendidos em programas de pós-graduação na Universidade Federal do Paraná, Universidade Estadual de Campinas e Universidade Gama Filho. A partir dos dados de nosso estudo, observamos uma modificação no cenário institucional. O Programa de Pós-Graduação em Ciência do Movimento Humano da Universidade Federal do Rio Grande do Sul desenvolveu nove pesquisas, sendo o que mais produziu teses e dissertações. Por outro lado, a Universidade Federal do Paraná conta com dois programas de pós-graduação, um na Educação Física e outro na Sociologia, sendo a instituição com o maior número de trabalhos defendidos no período analisado. 
Em relação às modalidades esportivas exploradas pelos pesquisadores, o futebol se apresenta como hegemônico, totalizando 21 trabalhos. Esta tendência demonstra uma continuidade, conforme apontado por Ferreira (2014), em que pese ser uma demonstração clara da visibilidade desse esporte no país. Os estudos considerados como "não especificado" aparecem na sequência e tratam de análises do esporte numa perspectiva genérica, não de uma modalidade em si. Natação, rúgbi, futebol americano e atletismo, somados, totalizaram oito estudos, sendo dois trabalhos de cada modalidade esportiva. Por fim, atletismo, basquetebol, capoeira, futsal, ginástica rítmica, skate, surfe, vôlei de praia e voleibol foram objeto de uma pesquisa cada, totalizando nove estudos (Figura 3):

Figura 3 - Modalidades Esportivas (2011-2018)

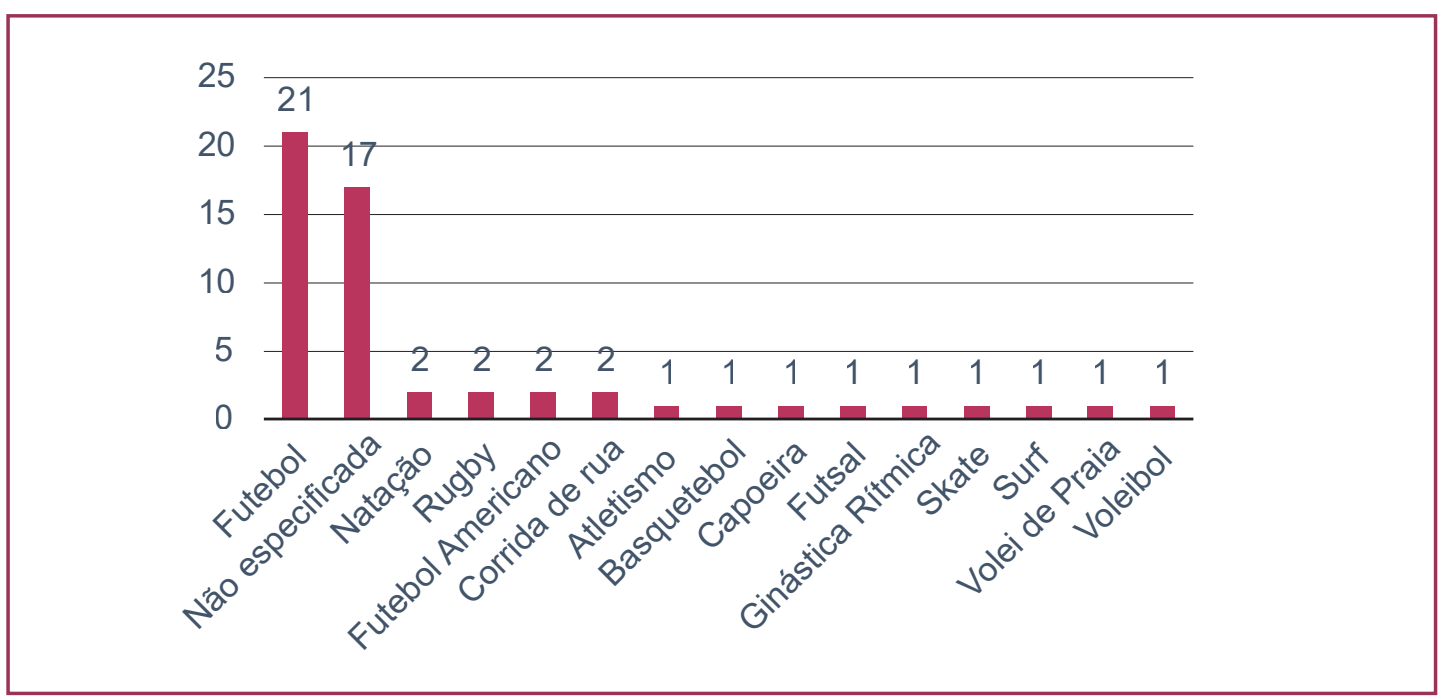

Fonte: dados da pesquisa

Observamos que rúgbi, futebol americano, skate e surfe surgem como objetos de estudo que até então não figuravam o rol de esportes tematizados nos programas de pós-graduação brasileiros com base na Sociologia do Esporte.

\subsection{CATEGORIAS SOCIOLÓGICAS PARA ANÁLISE DO CAMPO ESPORTIVO}

Apresentamos a seguir as categorias sociológicas adotadas para este trabalho (Quadro 2), mencionadas anteriormente, em que Almeida et al. (2016) e Marchi Júnior, Almeida e Souza (2019) revisam autores para fundamentar esta classificação. 
Quadro 2 - Número de estudos por categoria sociológica (2011-2018)

\begin{tabular}{|l|c|c|}
\hline \multicolumn{1}{c|}{ Categoria } & D & T \\
\hline Catarse e Violência & 4 & 1 \\
\hline Corporeidade & 1 & 2 \\
\hline Globalização & 4 & 2 \\
\hline Identidade & 5 & 1 \\
\hline Diversidade e Inclusão Social & 4 & - \\
\hline Racionalização & 8 & 2 \\
\hline Dominação Ideológica e Resistência & 5 & 1 \\
\hline Socialização e Distinção Social & 9 & 2 \\
\hline Outros & 2 & 1 \\
\hline Total & $\mathbf{5 4}$ & \\
\hline
\end{tabular}

Fonte: Baseado em Marchi Júnior, Almeida e Souza (2019).

Essas categorias serão discutidas e exemplificadas com estudos retirados do corpus de análise, ressaltando que tais trabalhos podem transitar em mais de uma categoria.

\subsubsection{Catarse e Violência}

Catarse e Violência fundamentam-se nos estudos de Bourdieu (2009) e Elias e Dunning (1992). Catarse, na concepção Aristotélica, referia-se ao efeito mimético proporcionado por manifestações artísticas como a música e o drama, sendo capazes de curar o corpo. Dessa forma, estaria associada ao "desencadeamento de emoções ou uma evocação da excitação, que provoca no corpo um efeito alegre e purificador" (ALMEIDA et al., 2016, p. 13).

Essa busca pela excitação, segundo Elias e Dunning (1992), não se limitaria às práticas de lutas e lazer, mas também estaria associada a uma série de práticas corporais da contemporaneidade que envolvem risco e manobras corporais, porém um risco controlado por aportes tecnológicos como forma de segurança. Práticas como surfe, skate, escalada e rapel, ou até mesmo o parkour, levam a liberar as tensões dos corpos. Pode-se entender que "a catarse é a manifestação de sentimentos socialmente reprimidos em ambientes sociais que permitem esse tipo de exposição, sendo o esporte, no momento de lazer, um espaço e um tempo privilegiado para isso" (MARCHI JÚNIOR, ALMEIDA e SOUZA 2019, p. 178).

Elias e Dunning (1992) associam a inclusão de regras de conduta ao esporte, advindas de um processo civilizador, como ganhos de ordem e autodisciplina, ao mesmo tempo em "que asseguravam o equilíbrio entre a possível obtenção de uma elevada tensão na luta e uma razoável proteção contra os ferimentos físicos" (ELIAS; DUNNING, 1992, p. 224). Para o sociólogo alemão, atos violentos são recuos no processo civilizatório, contendo pacificações como avanços do comportamento humano sobre o controle de pulsões, além de possibilitar sensibilizações à violência.

Nessa esteira percebemos que a violência é muito marcante dentro do campo esportivo, sendo possível identificá-la nas brigas entre torcidas, manifestada nos 
cânticos racistas e homofóbicos que visam diminuir e humilhar o adversário ou, até mesmo, no confronto físico direto. Tais elementos, para além da violência verbal, apontam-nos para uma violência simbólica, implícita, apresentando um caráter de obrigação, cujos efeitos se manifestam no aspecto psicológico (BOURDIEU, 2009).

Nesta categoria foram encontrados cinco estudos: uma tese sobre o surfe (MARCHI, 2017); duas dissertações sobre corrida de rua (OLIVEIRA, 2016; SANTOS, 2018); e duas dissertações que tematizam as torcidas de futebol, tendo em comum a questão identitária como uma categoria secundária (ALVES, 2014; SOUZA, 2014).

Como exemplo destacamos a tese de Marchi (2017), que situa o processo histórico de desenvolvimento do surfe ao tow-in, à luz da teoria do Processo Civilizador de Elias. A autora apresenta esta nova configuração social de um espírito de aventura, cuja vida está associada ao risco, prazer, aventura e emoção, advindas de um processo de espetacularização dos esportes de diferentes segmentos de mercados explorados por empresas que associam suas marcas e produtos a esse estilo de vida.

Ainda nesta categoria, com base na sociologia configuracional de Elias (2011), Alves (2014) procurou observar a relação da rivalidade e da violência entre as torcidas organizadas do Grêmio e do Internacional e a construção de suas identidades. Foram entrevistados torcedores dos dois clubes durante os jogos do Campeonato Brasileiro de Futebol nos anos de 2010, 2011 e parte de 2012. Foi destacado que a mídia local tem um papel preponderante para a formação das identidades e por manter acirrada as rivalidades entre os clubes. Nesse processo, o clássico "Grenal" foi vendido como um produto diferenciado, "o futebol do sul", frente ao futebol brasileiro, o que dificulta uma prática de negociação de conflitos entre as torcidas dos times em questão, uma vez que os confrontos violentos entre estas são traduzidos como marca constitutiva do espetáculo do futebol.

\subsubsection{Corporeidade}

Essa categoria tem como base a Sociologia do Corpo (LE BRETON, 2003, 2010), com ênfase nas discussões sobre a objetificação do corpo, o corpo máquina e a corpolatria. O sociólogo francês defende que o corpo é uma matéria prima a ser moldada, sendo resultado dos usos e das relações que seus agentes fazem e estabelecem com seus corpos, possibilitando compreender que as experiências e vivências se materializam no corpo e os gostos são externalizados por meio deste, moldado pelo consumo de uma corporeidade modal (ALMEIDA et al., 2016).

Foram classificados três estudos nesta categoria, sendo uma dissertação (COSTA, 2018a) e duas teses (ROGÉRIO, 2014; VLASTUIN, 2013). O estudo de Vlastuin (2013) analisou a trajetória de crescimento do voleibol feminino brasileiro, identificando os agentes e as estruturas que fazem parte desse contexto. Foram feitas entrevistas com atletas e ex-atletas que disputaram os Jogos Olímpicos entre 1980 e 2008, além de um dos gestores técnicos que estiveram à frente da Confederação Brasileira de Voleibol (CBV). Para análise dos dados, a autora se embasou na sociologia reflexiva de Bourdieu (1996, 2004, 2007), trabalhando com os conceitos de 
habitus, campo, ethos social, hexis corporal, capital, poder e reprodução social, e o conceito de gênero como uma categoria de análise cultural nesse contexto histórico.

O conceito de unidade de geração, proposto por Karl Mannheim (1986), foi utilizado para identificar e analisar as oito seleções de voleibol feminino brasileiro no recorte temporal demarcado. Como resultado, a autora evidenciou que a trajetória do voleibol feminino é "singular e independente do voleibol masculino, apesar de algumas estratégias de investimento (econômico, social e simbólico) serem parecidas" (VLASTUIN, 2013, p.194-195).

\subsubsection{Globalização}

Esta categoria emerge do fenômeno social de mesmo nome, sendo marcada por mudanças políticas, econômicas e sociais a partir do final do século XX que vêm moldando a existência humana em várias esferas, conforme é destacado por Bauman (1999), definindo a globalização como o "caráter indeterminado, indisciplinado e de autopropulsão dos assuntos mundiais; a ausência de um centro, de um painel de controle, de uma comissão diretora, de um gabinete administrativo" (BAUMAN, 1999, p. 66).

No contexto esportivo, uma das características da globalização é o televisionamento do esporte. As transmissões via satélite são importantes para a universalização das regras e o conhecimento e consumo de novas modalidades, ou de esportes que antes eram restritos a um determinado país. Em outras palavras, a mundialização da cultura esportiva foi alavancada pela globalização, conforme é apontado por Betti (1998, p. 28 apud ALMEIDA et al., 2016, p.26), que faz uma síntese ao escrever que "o esporte telespetáculo é também uma 'mercadoria desterritorializada'”. Ainda, podemos pensar a "crescente inter-relação internacional nas esferas cultural, econômica, política e social" como significado para o fenômeno da globalização (MARCHI JÚNIOR; ALMEIDA; SOUZA, 2019, p. 168).

Nesta categoria foram identificados seis estudos, sendo quatro dissertações (CAFEO, 2013; GUIOTI, 2016; PEREIRA, 2018; SALES, 2017) e duas teses (ROHER, 2016; ROSSETTO JUNIOR, 2016). Destacamos a dissertação de Guioti (2016), na qual o autor usa os casos de atletas "independentes", ou seja, que não têm representação de um comitê olímpico nacional, para contextualizar a globalização e suas implicações nos conceitos modernos de nacionalidade, pautados em território, na homogeneidade da população, em um ideal coletivo e na necessidade de um Estado-nação frente a uma nova ideia de nação na sociedade contemporânea. Para tanto, analisa a globalização em três âmbitos: político-econômico, sociocultural e esportivo.

\subsubsection{Identidade}

No Brasil, esta é uma categoria tradicionalmente associada à relação estabelecida ao futebol, a partir da modalidade em si ou diante dos atletas, por ter uma aproximação e identificação com o público consumidor, apesar de ser possível observar algumas mudanças de comportamento dos agentes nesse contexto, que 
se adaptam à estrutura. Nessa direção, ao pensarmos sobre a fluidez das relações humanas, Bauman (2005) advoga que a modernidade é algo a ser inventado, experimentado e não descoberto (ALMEIDA et al., 2016).

Para Castells (1999), a identidade está associada a um processo de construção de significados com aspectos culturais que se sobrepõem a outras maneiras de significação. Ele chama "de matéria-prima fornecida pela história, geografia, biologia, instituições produtivas e reprodutivas, pela memória coletiva e por fantasias pessoais" (ALMEIDA et al., 2016, p. 20). Tal concepção nos permite entender que existem identidades, e que elas podem ser construídas e reconstruídas pelos agentes conforme suas posições nas estruturas sociais; porém, há diferença entre identidade e papéis sociais, sendo que o mesmo agente pode ter mais de um papel social ao mesmo tempo, e que as identidades são mais significativas pois estão envoltas em um processo de autoconstrução e individualização.

Seis estudos foram localizados nesta categoria, sendo uma tese (MYSKIW, 2012) e cinco dissertações (FRANÇA, 2015; GUTIERREZ, 2016; MANEIRO, 2015; MORAIS; 2015; OLIVEIRA, 2013). A dissertação de Gutierrez (2016) versa sobre a observação do rúgbi, que era praticado inicialmente por estrangeiros e passa a ser assimilado por atletas brasileiros, criando uma identidade particular, ao mesmo tempo em que serviu de espaço para incluir estrangeiros que praticavam esse esporte nos seus países de origem. O referencial teórico do estudo está fundamentado na teoria dos campos, de Bourdieu (1990, 1996, 2003a); no conceito de nação, através de Anderson (2005); e de identidade, com Stuart Hall (1996, 2006).

Situando o rúgbi como um subcampo do campo esportivo, Gutierrez (2016) destaca simultaneamente que é criada uma identidade específica entre os praticantes da modalidade, compartilhando história e conjuntos de regras - que se modificam ao longo do tempo - num espaço social que é marcado pelas disputas constantes entre esses agentes.

\subsubsection{Diversidade e Inclusão Social}

O contexto da globalização aproxima essas duas categorias, na medida em que problematiza a exclusão social. A Diversidade pressupõe o respeito às diferentes características dos traços físicos, elementos culturais e elementos sociais, que não devem ser pautados em um padrão ideal, levando em consideração que "apesar de evidente pela intensa conexão e pelo intercâmbio de pessoas e informações, a diversidade por vezes, é origem de diferentes tipos de preconceito" (MARCHI JÚNIOR; ALMEIDA; SOUZA, 2019, p.144).

A Inclusão Social emerge a partir da discussão de justiça e mudanças sociais que tencionam um par dialético: inclusão e exclusão social. Enquanto incluir se refere a garantir a participação cidadã dos sujeitos com amplos direitos em uma sociedade, excluir remete "ao enfraquecimento da participação dos indivíduos nas redes sociais mais fundamentais do contexto em que vivem", não se limitando à pobreza (esfera econômica), mas, também, às questões de gênero, raça, etnia e sexualidade (ZIONI, 2006, p. 24 apud ALMEIDA et al., 2016, p. 22). 
Podemos perceber que os estudos que envolvem projetos sociais esportivos podem ser classificados a partir da categoria inclusão social; todavia, convém destacar que nem sempre esses projetos estão realmente incluindo, tanto pela submissão à lógica da mercantilização do esporte, que priva os menos favorecidos economicamente de consumi-lo (COLLINS, 2004), quanto pela submissão à heteronormatividade das regras esportivas que oprimem homossexuais, por exemplo (PRICE; PARKER, 2003).

Foram classificadas quatro dissertações nestas categorias (CARVALHO, 2013; LAZZARI, 2013; TONDIN, 2011; VIALICH, 2012). Carvalho (2013) analisou o desenvolvimento das políticas públicas de esporte a partir da criação da Constituição Federal de 1988 até a criação do Ministério do Esporte, em 2003. Nesse período, o esporte entra na agenda dos governos de maneira prioritária, levando a reestruturações e rearranjos institucionais do setor esportivo. Em suas análises, o autor contrasta as perspectivas esportivas do regime militar com as perspectivas democráticas, destacando, entre outras características o esporte como inclusão social, advinda da perspectiva do esporte educacional e do Esporte para Todos (EPT).

\subsubsection{Racionalização}

Esta é uma categoria que tem como base os estudos de Max Weber (2000, 2005) sobre o capitalismo no contexto da revolução industrial. Este referencial contribui para compreender a racionalização a partir da institucionalização das atividades produtivas sociais diante do distanciamento das relações pessoais, que passam a ser cada vez mais profissionais. Há uma valorização da especialização das tarefas e aperfeiçoamento técnico da execução e do controle da produção (SELL, 2012 apud ALMEIDA, et al., 2016).

A racionalização pode ser entendida como um meio para atingir um determinado fim, otimizando os processos produtivos, tendo a especialização das funções como uma de suas características. Também está associada ao modelo fordista e pode ser observada no esporte moderno, enfatizando o rendimento, produtividade e cientificidade.

A racionalidade no esporte, tematizada por Guttmann (2004), pode ser observada na disputa entre o amadorismo e o profissionalismo. Podemos destacar que o amadorismo perde espaço à medida que seus praticantes começam a ser organizados em federações e confederações, com a universalização das regras, com a cientificidade no treinamento e com a venda da força de trabalho dos esportistas, possibilitando a profissionalização.

Foram encontrados, nesta categoria, dez trabalhos, sendo duas teses (AFONSO, 2011; SONODA-NUNES, 2012) e oito dissertações (AZEVEDO FILHO, 2015; CAMPOS, 2015; CORREIA, 2016; COSTA, 2018b; MARTINS, 2016; MINA, 2017; RICCI, 2018; RIVITI, 2016).

O estudo de Afonso (2011) tem como pano de fundo as transformações do vôlei de praia ocorridas no final do século XX, como um produto mercantilizado e espetacularizado em escala global através dos meios de comunicação, principalmente 
a televisão. Para fundamentar sua pesquisa, o autor utilizou Weber $(2000,2005)$ para pensar um processo conjugado de racionalização-modernização, explicando o esporte como uma instituição moderna; e Guttmann (2004), ao apresentar as sete características do esporte moderno, quais sejam: secularização, igualdade de oportunidades, especialização, racionalização, organização burocrática, quantificação e superação de recordes.

\subsubsection{Dominação Ideológica e Resistência}

Essas categorias associam-se às disputas de poder que ocorrem no plano ideológico e que se manifesta por meio da alienação ou resistência.

Para pensar a dominação ideológica, os estudos marxistas, como os de Althusser (1974), servem de base. Segundo eles, a economia é fundamental para determinar as relações sociais, que ocorrem entre exploradores e explorados ou dominantes e dominados. Essa dominação se dá, também, no plano Ideológico, pois essas relações são naturalizadas e ensinadas em diversas instituições sociais. Reforçada por aparelhos ideológicos do Estado, é comum a utilização do esporte para benefício político, como ocorreu com o futebol nas ditaturas do Brasil e da Espanha no século XX. A ideia de dominação ideológica, segundo Almeida et al. (2016), pode ser atribuída à perpetuação e conquista de poder de dirigentes frente às organizações esportivas, como em federações e confederações.

Resistência, segundo Hollander e Einwoher (2004), é uma intenção de antagonismo a algo ou alguém através de uma ação, "que pode ser visível e reconhecida como oposição de imediato, como na forma de protestos, passeatas ou resistência verbalizada e gestual, mas também existem meios mais sutis, como a dissimulação, falsa cooperação, sabotagem ou indisposição" (ALMEIDA et al., 2016, p. 19). Segundo os autores, é necessário considerar o grau de intenção consciente por trás da resistência, que, apesar de difícil aferição, pode ser percebida por terceiros, mas não ser entendida pelos próprios indivíduos como resistência (ALMEIDA et al., 2016).

Foram identificados quatro estudos nesta categoria, sendo uma tese (SOUZA JÚNIOR, 2013) e cinco dissertações (CARNEIRO, 2011; COLOMBO, 2013; PINTO, 2018; RAPOSO, 2018; SALVINI, 2012). O trabalho de Pinto (2018) analisa as ações de grupos que, por meio de sua ação política em diferentes períodos históricos, reivindicaram o direito de torcer pelas pessoas LGBT e mulheres, desestabilizando, assim, a norma regulatória baseada em um modelo de masculinidade hegemônica.

O autor pesquisou o surgimento e desenvolvimento de torcidas organizadas em diferentes momentos históricos, e até mesmo no período do regime militar, em que a criação das torcidas Coligay (Grêmio) e Fla-gay (Flamengo) se apresentam como resistência aos padrões heterossexuais de masculinidade no futebol, até chegar em movimentos de torcedores contemporâneos contrários à homofobia e à misoginia no futebol brasileiro. 


\subsubsection{Socialização e Distinção Social}

Essas categorias emergem dos estudos de Durkheim ${ }^{4}$ (2010) e Bourdieu (2009). Para Durkheim (2010), o conceito de socialização estava relacionado à preparação das gerações mais novas por meio da educação (socialização metódica) física, intelectual e moral, para conviver no meio social em que estão inseridas. Tal ação era tarefa das gerações anteriores, que deveriam preparar o aspecto social dos indivíduos de acordo com as tradições, crenças, práticas morais e políticas presentes nos contextos em que estavam sendo socializados.

O esporte permite diferentes interações sociais, tanto para os que o praticam como para os que o consomem. Por outro lado, pode revelar elementos de distinção social. Para pensar esta noção, Bourdieu (2009) se interessou por investigar a fundo os estilos de vida, os gostos e o consumo de mais de dois mil entrevistados entre homens e mulheres franceses residentes de Paris e Lille entre 1963 e 1968. Podese entender que as práticas que são inacessíveis para os níveis sociais mais baixos caracterizam-se como luxuosas por sua raridade de consumo, sendo que esta "[...] prática só é distintiva quando subverte a ordem da necessidade e se concatena ao volume dos capitais econômico e cultural” (ALMEIDA et al., 2016, p. 15).

Quanto ao consumo de práticas esportivas, a noção de distinção nos auxilia a entender que as relações estabelecidas com o próprio corpo são impregnadas por um mimetismo social do que é distintivo ou vulgar, pois seus agentes acabam por reproduzir valores que já Ihes são caros em outras instâncias da vida social. Em outras palavras, a agressividade das lutas (como o boxe), práticas que expõem um corpo desprotegido, afastam agentes das classes dominantes que preferem se distinguir por valores de docilidade e práticas em que não haja contato físico, como o golfe, mantendo distância de seus oponentes (BOURDIEU, 1983, 2009; ALMEIDA et al., 2016).

Sinteticamente pode-se compreender a distinção social como uma categoria sociológica que, "se aplicada ao esporte, auxilia-nos na compreensão de que as escolhas para prática de modalidades esportivas têm relação com os grupos sociais de convivência", frequentemente associadas à condição financeira necessária para a prática (MARCHI JÚNIOR; ALMEIDA; SOUZA 2019, p. 191).

No corpus de análise, socialização e distinção social podem ser observadas em quase todos os trabalhos, estando vinculadas a outras categorias, como inclusão social, identidade, catarse e resistência. Nesse sentido, foram classificadas nove dissertações (BUENO, 2016; GOMES, 2013; JANUÁRIO, 2017; MARQUES, 2012; MORALES JÚNIOR, 2018; MORO, 2012; OLIVEIRA, 2018a; RAMPAZZO, 2012; ZAMBELLI, 2014) e duas teses (FORELL, 2014; KIOURANIS, 2017).

Zambeli (2014) desenvolveu um estudo etnográfico em que acompanhou um grupo de atletas da categoria máster de natação para compreender os significados atribuídos pelos participantes. Além de realizar entrevistas e observações, o pesquisador se inseriu no contexto da prática participando como competidor desta equipe.

4 Durkheim é considerado um dos expoentes a abordar a socialização como objeto de estudo (SETTON, 2005). 
Percebeu-se uma heterogeneidade de significados entre os membros da equipe, desde a participação em competições motivadas pela lógica do rendimento até aqueles que praticam a natação por diversão, convívio e manutenção da saúde. Havia atletas com 20 anos de idade (que já eram considerados masters), o que beneficiava a troca de experiências e o convívio entre diferentes gerações, elemento este valorizado pelos atletas mais jovens. O pesquisador destacou o potencial deste esporte na modalidade mista (revezamento entre dois homes e duas mulheres) para tematizar as relações de gênero em futuras pesquisas.

\subsubsection{Ecologização e Secularização}

No interior do campo esportivo, a categoria ecologização está relacionada aos estudos que envolvem as Atividades Físicas de Aventura na Natureza (AFAN), cujas práticas pretendem reaproximar o sujeito aos ambientes naturais. Essa separação se deu como uma das consequências da especialização do trabalho, à medida que os indivíduos vão compreendendo e explicando os fenômenos naturais, colocandose numa situação dominante em relação à natureza. Tais práticas advogam o restabelecimento das relações de convivência e coexistência na construção de sentidos e significados culturais.

Autores que trabalham nessa perspectiva compreendem que "apenas uma nova organização da sociedade e do espaço geográfico, associados a um novo papel do Estado, criará as condições para o surgimento de uma nova relação homem/ natureza, mais harmoniosa" (GONÇALVES-DIAS 2008, p. 153). São intitulados de ecomarxistas pois compreendem que a natureza é transformada em mercadoria para a exploração capitalista.

A categoria secularização emerge dos estudos de Weber $(1974,2005)$ que tratam do desenvolvimento do capitalismo e, mais uma vez, apropriada por Guttmann (2004) ao caracterizar o esporte moderno. Pode ser entendida como rompimento, diminuição e/ou distanciamento da influência da religião sobre a sociedade moderna, manifestos numa laicização do Estado e suas instituições, revelando novas formas de relações sociais. No campo esportivo, Guttmann (2004) destaca que os rituais sacros, presentes nas práticas corporais da antiguidade, como os jogos olímpicos gregos, passam para um segundo plano, uma vez que não estão mais associados aos objetivos finais das competições esportivas e dos próprios atletas, mesmo que alguns manifestem suas crenças religiosas e o discurso midiático tente criar personagens sagrados em suas narrativas, especialmente para os vencedores (ALMEIDA et al., 2016).

As categorias ecologização e secularização não foram identificadas no corpus de análise dos trabalhos levantados neste estudo.

\subsubsection{Outros}

Nesta categoria classificamos três estudos ${ }^{5}$ que não se enquadravam nas descrições das categorias sociológicas para uma análise do campo esportivo, conforme Marchi Júnior, Almeida e Souza (2019). Estes estudos são caracterizados

5 Sendo duas dissertações (BRASIL, 2018 e OLIVEIRA, 2018) e uma tese (FERREIRA, 2014). 
por desenvolver leituras a respeito de mapeamentos da produção do conhecimento em torno da Sociologia do Esporte.

Ferreira (2014) analisou o processo de constituição da Sociologia do Esporte como um subcampo acadêmico-científico no Brasil entre os anos de 1980 e 2010, localizando os centros de produção científica, seus principais agentes, as correntes teóricas que permeiam os estudos desenvolvidos e as relações entre essas pesquisadores e instituições. Neste sentido, a conformação do subcampo da Sociologia do Esporte estava situada entre os agentes que atuam nos cursos de pós-graduação em Educação Física, majoritariamente, e Sociologia, conferindo uma característica híbrida no interior deste processo.

Os estudos desenvolvidos por Oliveira (2018b) e Brasil (2018) buscaram analisar a recepção dos referenciais teóricos dos sociólogos Norbert Elias no campo acadêmico-científico brasileiro e Pierre Bourdieu no interior do subcampo científico da Educação Física brasileira, respectivamente. Oliveira (2018b) concluiu que a inserção das discussões em torno do trabalho desenvolvido por Elias, no Brasil, ocorre na década de 1990 por pesquisadores do Programa de Pós-Graduação em Educação Física da Universidade Estadual de Campinas. Brasil (2018) evidenciou que a utilização do referencial bourdieusiano na Educação Física se dá através da sociologia do esporte e do corpo, tendo na Universidade Estadual de Campinas e na Universidade Federal do Paraná os principais centros de produção científica observados.

\section{CONSIDERAÇÕES FINAIS}

Diante do mapeamento das pesquisas sobre a Sociologia do Esporte nos programas de pós-graduação brasileiros entre 2011 e 2018 e a partir das categorias sociológicas para análise do campo esportivo sugeridas por (ALMEIDA et al., 2016; MARCHI JÚNIOR; ALMEIDA; SOUZA, 2019), elencamos alguns pontos de destaque, a seguir.

Sobre as modalidades, o futebol continua sendo o esporte mais estudado, demonstrando a sua hegemonia diante das escolhas dos pesquisadores envolvidos, embora esportes menos populares, como rúgbi, futebol americano, skate e surfe apareçam como objetos de estudos sociológicos inéditos para o subcampo acadêmico-científico da Sociologia do Esporte.

Diante das categorias sociológicas utilizadas, racionalização, identidade, socialização e globalização se apresentam com maior frequência nas pesquisas, enquanto as categorias resistência, distinção social, inclusão social, corporeidade, catarse e violência aparecem com menor incidência. Observamos que há uma lacuna sobre estudos que podem envolver as categorias e ecologização e secularização, com o intuito de ampliar temas que possibilitem o desenvolvimento da Sociologia do Esporte no Brasil.

Os estudos que se enquadraram na categoria "outros", envolvendo a análise da produção do conhecimento, embora não estejam classificados a partir das categorias sociológicas, podem indicar um novo campo de análise no interior da Sociologia do 
Esporte. Este movimento possibilita uma vigilância epistemológica (BOURDIEU, 2015), no sentido de potencializar a construção de novos objetos de estudos.

Por fim, para estudos futuros, sugerimos o aprofundamento para responder lacunas que surgiram no presente estudo, quais sejam: investigar os impactos gerados na Sociologia do Esporte a partir das contribuições de outras áreas do conhecimento; evidenciar as motivações sociológicas para o aparecimento de esportes como o rúgbi, futebol americano, skate e surfe, levando em consideração que as práticas científicas acabam por expressar dinâmicas culturais presentes no meio social.

\section{REFERÊNCIAS}

AFONSO, Gilmar Francisco. A reinvenção do Voleibol de praia: agentes e estruturas de uma modalidade espetacularizada (1983-2008). 2011. Tese (Doutorado em Sociologia) Pós-Graduação em Sociologia, Setor de Ciências Humanas, Letras e Artes, Universidade Federal do Paraná Curitiba, 2011. Disponível em: http://www.humanas.ufpr.br/portal/pgsocio/ files/2013/07/tese-pronta.pdf/. Acesso em: 25 mar. 2021.

ALMEIDA, Barbará Schausteck de; SALVINI, Leila; KIOURANIS, Taíza Daniela Seron; MARCHI JÚNIOR, Wanderley. Possíveis categorias sociológicas para análise do campo esportivo. In: BETINE, Marco (org.). Estudos interdisciplinares do esporte: aspectos filosóficos, sociais, políticos e econômicos São Paulo: USP, 2016. Disponível em: https:// www.researchgate.net/publication/304783676_Possiveis_categorias_sociologicas_para_ analise_do_campo_esportivol. Acesso em: 25 mar. 2021.

ALTHUSSER, Louis. Ideologia e aparelhos ideológicos do estado (notas para uma investigação). Lisboa: Editorial Presença, 1974.

ALVES, Cristina Cordeiro. "Posso morrer pelo meu time": a construção social da rivalidade clubística entre Grêmio e Internacional e a sua relação com as violências no futebol. 2014. Dissertação (Mestrado em Ciência do Movimento Humano) - Escola de Educação Física, Fisioterapia e Dança, UFRGS, Porto Alegre, 2014. Disponível em: https:// lume.ufrgs.br/handle/10183/103914/. Acesso em: 25 mar. 2021.

ANDERSON, Benedict. Comunidades imaginadas: reflexões sobre a origem e a difusão da nação. Lisboa: Edições 70, 2005.

AZEVEDO FILHO, Luiz Felipe Faria de. Políticas de esporte em alto rendimento: reflexos na qualidade de vida de ex-atletas. 2015. Dissertação (Mestrado em Sociologia Política) Universidade Vila Velha, Vitória, 2015. Disponível em: https://sucupira.capes. gov.br/sucupira/public/consultas/coleta/trabalhoConclusao/viewTrabalhoConclusao. isf?popup=true\&id trabalho=2517664\#. Acesso em: 25 mar. 2021.

BAUMAN, Zygmunt. Globalização: as consequências humanas. Rio de Janeiro: Jorge Zahar Editor, 1999.

BAUMAN, Zygmunt. Identidade. Entrevista a Benedetto Vecchi. Rio de Janeiro: Jorge Zahar Editor, 2005.

BETTI, Mauro. A janela de vidro. Campinas: Papirus, 1998. 
BOURDIEU, Pierre. A distinção: crítica social do julgamento. Porto Alegre: Zouk, 2009.

BOURDIEU, Pierre. A dominação masculina. 5. ed. Rio de Janeiro: Bertrand Brasil, 2007.

BOURDIEU, Pierre. A produção da crença: contribuição para uma economia dos bens simbólicos. 2. ed. São Paulo: Zouk, 2004.

BOURDIEU, Pierre. Como se pode ser desportista? In: BOURDIEU, Pierre. Questões de sociologia. Lisboa: Fim do século, 2003a. p. 181-204.

BOURDIEU, Pierre. Programa para uma sociologia do esporte. In: BOURDIEU, Pierre. Coisas ditas. São Paulo: Brasiliense, 1990. p. 207-220.

BOURDIEU, Pierre. Razões práticas: sobre a teoria da ação. 9. ed. São Paulo: Papirus, 1996.

BOURDIEU, Pierre. Usos sociais da ciência. São Paulo: Unesp, 2003b.

BRASIL, Marcos Roberto. Os usos da teoria sociológica de Pierre Bourdieu na área de educação física no Brasil (1977-2017). 2018. Dissertação (Mestrado em Educação Física) - Universidade Estadual de Londrina, Maringá, 2018. Disponível em: https://www. researchgate.net/publication/331047392_os_usos_da teoria_sociologica_de_pierre bourdieu_na_area_de_educacao_fisica_no_brasil_1977-2017/. Acesso em: 25 mar. 2021.

BUENO, Igor Alexandre Silva. O futebol americano em Cuiabá Mato Grosso: a construção de uma demanda esportiva. 2016. Dissertação (Mestrado em Estudos de Cultura Contemporânea) - Universidade Federal de Mato Grosso, Cuiabá, 2016. Disponível em: https://ri.ufmt.br/handle/1/1976/. Acesso em: 25 mar. 2021.

CAFEO, Marta Regina Garcia. O riso pela fama: análise dos filmes publicitários da Topper e Confederação Brasileira de Rugby. 2013. Dissertação (Mestrado em Comunicação) - Faculdade de Arquitetura, Artes e Comunicação, Universidade Estadual Paulista Julio de Mesquita Filho, Bauru, 2013. Disponível em: https://repositorio.unesp.br/ handle/11449/89504/. Acesso em: 25 mar. 2021.

CAMPOS, Marcos Miguel Guimarães. Análise dos gastos em esporte e lazer nos municípios de Minas Gerais nos anos de 2008 a 2012. 2015. Dissertação (Mestrado em Sociologia Política) - Centro de Filosofia e Ciências Humanas, Universidade Federal de Santa Catarina, Florianópolis, 2016. Disponível em: https://repositorio.ufsc.br/ handle/123456789/169340/. Acesso em: 25 mar. 2021.

CARNEIRO, Tarcísio Arquimedes Araújo. Futebol no Bom Jardim: prática de sociabilidade e estratégia de Política Pública Social. 2011. Dissertação (Mestrado em Sociologia) - Universidade Estadual do Ceará, Fortaleza, 2011. Disponível em: https://

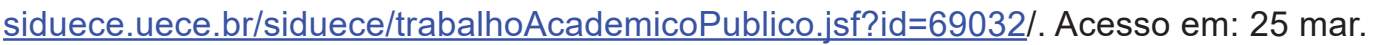
2021.

CARVALHO, César Machado de. Esporte como política pública: um estudo sobre o processo de formulação da política de esporte no Brasil. 2013. Dissertação (Mestrado em Ciência Política) - Universidade Federal de São Carlos, São Carlos, 2013. Disponível em: https://repositorio.ufscar.br/handle/ufscar/1024/. Acesso em: 25 mar.2021.

CASTELLS, Manuel. O poder da identidade. São Paulo: Paz e Terra, 1999.

COLLINS, Mike. Sport, physical activity and social exclusion. Journal of Sports Sciences, v. 22, n. 8, p. 727-740, 2004. DOI: https://doi.org/10.1080/02640410410001712430. 
COLOMBO, Luis Oscar Calvano. A produção de subjetividade está em jogo: o Globo Esporte por uma ótica filosófica. 2013. Dissertação (Mestrado em Educação) - Universidade Estadual do Rio de Janeiro, Rio de Janeiro, 2013. Disponível em: http://bdtd.ibict.br/vufind/ Record/UERJ_bf0c449ab5688a0f27bfdc81d943a64a/. Acesso em: 25 mar. 2021.

CORREIA, Roberto Lúcio. Uma análise da formulação e dos processos de implementação do Plano Brasil Medalhas 2016. 2016. Dissertação (Mestrado em Ciência do Movimento Humano) - Escola de Educação Física, Fisioterapia e Dança, Universidade Federal do Rio Grande do Sul, Porto Alegre, 2016. Disponível em: https://www.lume.ufrgs.br/ handle/10183/150959/. Acesso em: 25 março 2021.

COSTA, Caroline Ruivo. A arbitragem em ginástica rítmica no Brasil: uma abordagem configuracional. 2018a. Dissertação (Mestrado em Educação Física) - Universidade Estadual de Londrina, UEL-UEM, Maringá, 2018.

COSTA, Isabel Plociniaki. Fatores determinantes para o êxito nos Jogos Escolares do Paraná a partir da perspectiva dos professores: o caso da natação e do atletismo. 2018b. Dissertação (Mestrado em Educação Física) - Universidade Federal do Paraná, Curitiba, 2018. Disponível em: https://acervodigital.ufpr.br/handle/1884/58127/. Acesso em: 25 março 2021.

DURKHEIM, Émile. Textos selecionados. In: FILLOUX, J. C. Émile Durkheim. Trad. Maria Lucia Sales Boudet. Recife: Fundação Joaquim Nabuco, Editora Massangana, 2010.

ELIAS, Norbert. Introdução à sociologia. Lisboa: Edições 70, 2011.

ELIAS, Norbert; DUNNING, Eric. A busca da excitação. Lisboa: DIFEL, 1992.

FERREIRA, Ana Letícia Padeski. O campo acadêmico-científico da sociologia do esporte no Brasil (1980-2010): entre a institucionalização, os agentes e a sua produção. 2014. Tese (Doutorado em Sociologia) - Universidade Federal do Paraná, Curitiba, 2014. Disponível em: https://acervodigital.ufpr.br/handle/1884/35877/. Acesso em: 25 mar. 2021.

FERREIRA, Ana Letícia Padeski. O Estado da Arte da Sociologia do Esporte no Brasil: um mapeamento da produção bibliográfica de 1997 a 2007. 2009. Dissertação (Mestrado em Sociologia). Universidade Federal do Paraná, Curitiba, 2009. Disponível em: https:// acervodigital.ufpr.br/handle/1884/18362/. Acesso em: 25 março 2021.

FORELL, Leandro. Participando na cidade: um estudo etnográfico sobre a participação em Políticas Públicas de Esporte e Lazer no Parque Ararigbóia em Porto Alegre/RS. 2014. Tese (Doutorado em Ciência do Movimento Humano) - Escola de Educação Física, Fisioterapia e Dança, Universidade Federal do Rio Grande do Sul, Porto Alegre, 2014. Disponível em: https://www.lume.ufrgs.br/handle/10183/108525/. Acesso em: 25 mar. 2021.

FRANÇA, Mateus Trevisan. Processos de constituição do basquetebol na cidade do Rio Grande/RS (1960-1980): memórias clubísticas. 2015. Dissertação (Mestrado em Educação Física) - Universidade Federal do Paraná, Curitiba, 2015. Disponível em: https:// acervodigital.ufpr.br/handle/1884/40962/. Acesso em: 25 março 2021.

GOMES, Lívio Rodrigues. Entre campos e cantos: para uma sociologia do futebol amador. 2013. Dissertação (Mestrado em Sociologia) - Universidade Federal de Minas Gerais, Belo Horizonte, 2013. Disponível em: https://repositorio.ufmg.br/handle/1843/BUOS-99BFB4/. Acesso em: 25 março 2021.

GONÇALVES-DIAS, Sylmara Lopes Francelino. Um convite à reflexão sobre o dilema "sociedade ou natureza". RAE - Revista de Administração de Empresas, v. 48, n. 2, p. 152-153, 2008. DOI: http://dx.doi.org/10.1590/S0034-75902008000200010. 
GUIOTI, Tiago Del Tedesco. A nação olímpica: o caso dos atletas independentes olímpicos. 2016. Dissertação (Mestrado interdisciplinar em Ciências Humanas e Sociais) Universidade Estadual de Campinas, Campinas, 2016.

GUTIERREZ, Diego Monteiro. O Rugby, identidade e processos econômicos no Brasil. 2016. Dissertação (Mestrado) - Escola de Artes, Ciências e Humanidades, Universidade de São Paulo, São Paulo, 2016. Disponível em: https://www.teses.usp.br/teses/ disponiveis/100/100134/tde-18082016-170712/pt-br.php/. Acesso em: 25 março 2021.

GUTTMANN, Allen. From ritual to record: the nature of modern sports. New York/ Chichester: Columbia University, 2004.

HALL, Stuart. A identidade cultural na pós-modernidade. Rio de Janeiro: Lamparina 2006.

HALL, Stuart; GAY, Paul Du (ed). Questions of cultural identity. London: Sage, 1996.

HOLLANDER, Jocelyn A.; EINWOHNER, Rachel L. Conceptualizing resistance. In: Sociological forum. Kluwer Academic Publishers-Plenum Publishers, 2004. p. 533-554. Disponível em: https://link.springer.com/content/pdf/10.1007/s11206-004-0694-5.pdf. Acesso em: 18 mar. 2021.

JANUARIO, Jéssica dos Anjos. A herança na trajetória esportiva de Grandes Mestres brasileiros: processos educacionais e esportivos de formação de uma elite cultural. 2017. Dissertação (Mestrado em Educação) - Universidade de São Paulo, Ribeirão Preto, 2017. Disponível em: https://repositorio.usp.br/item/002866934/. Acesso em: 25 mar. 2021.

KIOURANIS, Taíza Daniela Seron. Os jogos escolares brasileiros chegam ao século XXI: reprodução ou modernização na política de esporte escolar? 2017. Tese (Doutorado em Educação Física) - Universidade Federal do Paraná, Curitiba 2017. Disponível em: https://acervodigital.ufpr.br/handle/1884/47355. Acesso em: 25 mar. 2021.

LAZZARI, André. A heterogeneidade de significados da prática futebolística num programa social esportivo: possibilidades de articulações e de sustentação do programa. 2013. Dissertação (Mestrado em Ciência do Movimento Humano) - Escola de Educação Física, Fisioterapia e Dança, Universidade Federal do Rio Grande do Sul, Porto Alegre, 2013. Disponível em: https://www.lume.ufrgs.br/handle/10183/88840/. Acesso em: 25 março 2021.

LE BRETON, David. A sociologia do corpo. 4. ed. Petrópolis: Vozes, 2010.

LE BRETON, David. Adeus ao corpo: antropologia e sociedade. Campinas: Papirus, 2003.

MANEIRO, Cristian. Futebol e identidade nacional no Uruguai (2010-2013): ressurgimento, consolidação e rupturas. 2015. Dissertação (Mestrado em Sociologia) Universidade Federal do Paraná, Curitiba, 2015. Disponível em: https://acervodigital.ufpr.br/ handle/1884/37938/. Acesso em: 25 março 2021.

MANNHEIM, Karl. Sociologia do conhecimento. Porto: Rés, 1986. v. 2.

MARCHI, Katia Bortolotti. Do surf ao tow-in: do processo civilizador à sociedade de risco. 2017. Tese (Doutorado em Educação Física) Universidade Federal do Paraná, Curitiba, 2017. Disponível em: https://acervodigital.ufpr.br/handle/1884/47361/. Acesso em: 25 mar. 2021.

MARCHI JÚNIOR, Wanderley. Campo Esportivo. In: CATANI, Afrânio. Mendes et al. Vocabulário Bourdieu. Belo Horizonte: Autêntica, 2017. p. 79-81. 
MARCHI JÚNIOR, Wanderley. O esporte "em cena": perspectivas históricas e interpretações conceituais para a construção de um Modelo Analítico. The journal of the Latin American socio-cultural studies of sport (ALESDE), v. 5, n. 1, p. 46-67, 2016. Disponível em: https:// revistas.ufpr.br/alesde/article/view/43890. Acesso em 25 mar. 2021.

MARCHI JÚNIOR, Wanderley; ALMEIDA, Bárbara.; SOUZA, Juliano. Introdução à sociologia do esporte. Curitiba: Intersaberes, 2019.

MARCONI, Mariane de Andrade; LAKATOS, Eva Maria. Fundamentos da metodologia científica. 5 ed. São Paulo: Atlas, 2003.

MARQUES, Elder Régis Deorato. Projetos sociais esportivos: um estudo das relações entre o esporte e o autoconceito. 2012. Dissertação (Mestrado em Ciências) - Escola de Educação Física e Esporte, Universidade de São Paulo, São Paulo, 2012. Disponível em: https://www.teses.usp.br/teses/disponiveis/39/39134/tde-15052012-072907/pt-br.php. Acesso em: 25 mar. 2021.

MARTINS, Mariane Goettert. Campeonato municipal de futebol de várzea de Porto Alegre: uma abordagem sócio-histórica (1993-2014). 2016. Dissertação (Mestrado em Ciência do Movimento Humano) - Escola de Educação Física, Fisioterapia e Dança, Universidade Federal do Rio Grande do Sul, Porto Alegre, 2016. Disponível em: https://www. lume.ufrgs.br/handle/10183/150967/. Acesso em: 25 mar. 2021.

MEDEIROS, Cristina; GODOY, Letícia. As referências de Pierre Bourdieu e Norbert Elias na Revista Brasileira de Ciências do Esporte: mapeando tendências de apropriação e de produção de conhecimento na área de Educação Física (1979-2007). Revista Brasileira de Ciências do Esporte, v. 30, n. 2, p. 199 - 214, 2009. Disponível em: http://revista.cbce.org. br/index.php/RBCE/article/view/445/361/. Acesso em: 25 mar. 2021.

MINA, Renan Vidal. A bola e os trilhos: a incorporação do futebol em Rio Claro e o desenvolvimento do Rio Claro Futebol Clube. 2017. Dissertação (Mestrado em Mudança Social e Participação Política) - Universidade de São Paulo, São Paulo, 2017. Disponível em: https://bdtd.ibict.br/vufind/Record/USP_9d2b2a25864596232db7517e00ae98ad/. Acesso em: 25 mar. 2021.

MORAIS, Diego Batista de. O jogo na arquibancada: o setor alvinegro e as performances do torcer no contexto do futebol espetacularizado. 2015. Dissertação (Mestrado em Sociologia) - Universidade Federal do Ceará, Fortaleza, 2015. Disponível em: http://www. repositorio.ufc.br/handle/riufc/12904/. Acesso em: 25 mar. 2021.

MORALES JÚNIOR, Valter Ruiz. O subcampo do futebol americano no estado de São Paulo entre 2015 a 2017: rupturas, aproximações e disputas por poder entre ligas e federação. 2018. Dissertação (Mestrado em Ciências) - Escola de Educação Física e Esporte de Ribeirão Preto, Universdade de São Paulo, Ribeirão Preto, 2018. Disponível em:https://www.teses.usp.br/teses/disponiveis/109/109131/tde-16042018-142601/pt-br.php/. Acesso em: 25 mar. 2021.

MORO, Luize. Conhecendo os parques de Curitiba e seus espaços públicos destinados às brincadeiras infantis. 2012. Dissertação (Mestrado em Educação Física) - Programa de Pós-Graduação em Educação Física, Universidade Federal do Paraná, Curitiba, 2012. Disponível em: https://acervodigital.ufpr.br/handle/1884/27529/. Acesso em: 25 mar. 2021.

MYSKIW, Mauro. Nas controvérsias da várzea: Trajetórias e retratos etnográficos em um circuito de futebol da cidade de Porto Alegre. 2012. Tese (Doutorado em Ciências do Movimento Humano) - Escola de Educação Física, Fisioterapia e Dança, Universidade Federal do Rio Grande do Sul, Porto Alegre, 2012. Disponível em: https://www.lume.ufrgs.br/ handle/10183/67002/. Acesso em: 25 mar.2021. 
OLIVEIRA, Fábio Eloide. Publicidade, imaginário e identidades nacionais: o futebol e a religiosidade em tempos de copa do mundo. 2013. Dissertação (Mestrado em Comunicação Social) - Universidade Metodista de São Paulo, 2013. Disponível em: http://tede.metodista. br/jspui/handle/tede/664/. Acesso em: 25 mar. 2021.

OLIVEIRA, Karina Barbosa de. Um bichinho me pegou: a escolha e a permanência no universo das corridas de rua. 2016. Dissertação (Mestrado em Estudos do Lazer) - Universidade Federal de Minas Gerais, Belo Horizonte, 2016. Disponível em: https:// repositorio.ufmg.br/handle/1843/BUOS-B24GDF/. Acesso em: 25 mar. 2021.

OLIVEIRA, Sizernandes Freire de. Aspectos sociais e culturais sobre o futebol amador em Cuiabá: um estudo sobre o campeonato de futebol peladão. 2018. Dissertação (Mestrado em Estudos de Cultura Contemporânea) - Universidade Federal do Mato Grosso, Cuiabá, 2018a. Disponível em:https://sucupira.capes.gov.br/sucupira/public/consultas/coleta/ trabalhoConclusao/viewTrabalhoConclusao.jsf?popup=true\&id trabalho=7019626. Acesso em: 25 mar. 2021.

OLIVEIRA, Vinícius Machado de. A recepção do trabalho de Norbert Elias no Brasil: movimentos figuracionais a partir da área de Educação Física. 2018. Dissertação (Mestrado em Educação Física) - Universidade Estadual de Maringá, Maringá, 2018b. Disponível em: https://sucupira.capes.gov.br/sucupira/public/consultas/coleta/trabalhoConclusao/ viewTrabalhoConclusao.jsf?popup=true\&id trabalho=6346937. Acesso em: 25 mar. 2021.

PEREIRA, Tatiane de Assis. Entre a arte do esporte e o jogo da capoeira: aproximações e distanciamentos a partir de um olhar polissêmico. 2018. Dissertação (Mestrado em Educação Física) - Universidade Federal do Paraná, Curitiba, 2018. Disponível em: https:// acervodigital.ufpr.br/handle/1884/59788/. Acesso em: 25 mar. 2021.

PINTO, Maurício Rodrigues. Pelo direito de torcer: das torcidas gays aos movimentos de torcedores contrários ao machismo e à homofobia no futebol. 2018. Dissertação (Mestrado em Mudança Social e Participação Política) - Escola de Artes, Ciências e Humanidades, Universidade de São Paulo, São Paulo, 2017. Disponível em:https://www. teses.usp.br/teses/disponiveis/100/100134/tde-12032018-205408/pt-br.php/. Acesso em: 25 mar. 2021.

PRICE, Michael; PARKER, Andrew. Sport, sexuality, and the gender order: amateur rugby union, gay men, and social exclusion. Sociology of Sport Journal, v. 20, p. 108-126, 2003. DOI:https://doi.org/10.1123/ssj.20.2.108.

RAMPAZZO, Marcelo. Skate, uma prática no lazer da juventude: um estudo etnográfico. 2012. Dissertação (Mestrado em Ciência do Movimento Humano) - Escola de Educação Física, Fisioterapia e Dança, Universidade Federal do Rio Grande do Sul, Porto Alegre, 2012. Disponível em: https://lume.ufrgs.br/handle/10183/63159/. Acesso em: 25 mar. 2021.

RAPOSO, Clarissa Carramilo. Cobertura midiática das Olimpíadas Rio 2016: a imagem da jogadora de futebol pela imprensa no Brasil e nos Estados Unidos. 101 f. 2018. Dissertação (Programa de Pós-Graduação em Ciências Sociais/CCH) - Universidade Federal do Maranhão, São Luís, 2018.

RICCI, Cristiano Streb. O futsal no ambiente escolar extracurricular: as perspectivas e objetivos de ensino de Instrutores/Treinadores atuantes em escolas particulares da cidade de Ribeirão Preto/SP. 2018. Dissertação (Mestrado em Educação) - Faculdade de Filosofia, Ciências e Letras de Ribeirão Preto, Universidade de São Paulo, Ribeirão Preto, 2018.

Disponível em:https://teses.usp.br/teses/disponiveis/59/59140/tde-19042018-094029/pt-br. php/. Acesso em: 25 mar. 2021. 
RIVITI, Thiago Garcia. Futebol brasileiro na atualidade: história, cultura e profissionalização. 2016. Dissertação (Mestrado em Psicologia) - Faculdade de Ciências e Letras - Assis, UNESP, Assis, 2016. Disponível em: https://repositorio.unesp.br/ handle/11449/141500/. Acesso em: 25 mar. 2021.

ROGÉRIO, Radamés de Mesquita. No "segundo tempo da vida": o jogador de futebol e a passagem para a pós-carreira. 2014. Tese (Doutorado em Sociologia) - Universidade Federal do Ceará, Fortaleza, 2014. Disponível em: http://www.repositorio.ufc.br/handle/ riufc/10561/. Acesso em: 25 mar. 2021.

ROHRER, Cleber Vanderlei. O futebol: cultura e convergência das mídias. 2016. Tese (Doutorado em Comunicação e Semiótica) - Faculdade de Filosofia, Comunicação, Letras e Artes, Pontifícia Universidade Católica de São Paulo, São Paulo, 2016. Disponível em: https://sapientia.pucsp.br/handle/handle/19612/. Acesso em: 25 mar. 2021.

ROSSETTO JÚNIOR, Adriano José. Copa do Mundo Fifa-Brasil 2014: realidades, mitos e legados na cidade de São Paulo. 2016. Tese (Doutorado em Ciências Sociais) - Faculdade de Ciências Sociais, Pontifícia Universidade Católica de São Paulo, São Paulo, 2016. Disponível em: https://tede2.pucsp.br/handle/handle/19643/. Acesso em: 25 mar. 2021.

SALES, Boaz Galo de Souza. A mancha no manto: a mercantilização do futebol por meio do patrocínio na camisa. 2017. Dissertação (Mestrado em Ciências) - Escola de Artes, Ciências e Humanidades, Universidade de São Paulo, São Paulo, 2017. Disponível em: https://www.teses.usp.br/teses/disponiveis/100/100134/tde-24012018-181047/pt-br.php/. Acesso em: 25 mar. 2021.

SALVINI, Leila. Novo Mundo Futebol Clube e o velho mundo do futebol: considerações sociológicas sobre o habitus esportivo de jogadoras de futebol. 2012. Dissertação (Mestrado em Educação Física) - Universidade Federal do Paraná, Curitiba, 2012. Disponível em: https://www.acervodigital.ufpr.br/handle/1884/27397/. Acesso em: 25 mar. 2021.

SANTOS, Mikael Corrêa. Corrida de rua: esporte, diversão e consumo. Análise das campanhas publicitárias "It's Runderful" da Mizuno e "Vem Junto" da Nike. 2018. Dissertação (Mestrado em Comunicação) - Universidade Estadual Paulista, Bauru, 2018. Disponível em: https://repositorio.unesp.br/handle/11449/157279/. Acesso em: 25 mar. 2021.

SELL, Carlos Eduardo. Racionalidade e racionalização em Max Weber. Revista Brasileira de Ciências Sociais, v. 27, n. 79, p. 153-233, 2012. DOI:https://doi.org/10.1590/S0102$\underline{69092012000200010 .}$

SETTON, Maria da Graça Jacintho. A particularidade do processo de socialização contemporâneo. Tempo social, v. 17, p. 335-350, 2005. DOI: https://doi.org/10.1590/S0103$\underline{20702005000200015}$

SONODA-NUNES, Ricardo João. "Sport for all”: as relações entre SESI e CSIT no campo esportivo (1996-2011). 2012. Tese (Doutorado em Sociologia) - Universidade Federal do Paraná, Curitiba, 2012. Disponível em: https://acervodigital.ufpr.br/handle/1884/29285/. Acesso em: 25 mar. 2021.

SOUZA, Gustavo César Arêas de. Em nome da excitação: uma etnografia da relação política entre torcedores organizados e dirigentes de futebol. 2014. Dissertação (Mestrado em Ciências Sociais) - Universidade Federal Rural do Rio de Janeiro, Seropédica, 2014. Disponível em: https://tede.ufrrj.br/jspui/handle/jspui/2138/. Acesso em: 25 março 2021.

SOUZA, Juliano de. A reflexividade metodológica de Pierre Bourdieu como modelo heurístico para leitura do esporte no Brasil: potencialidade e contribuições. In: MARCHI JÚNIOR, Wanderley (org.). Ensaios em sociologia do esporte. São Paulo: Factash, 2011. p. 29-53. 
SOUZA, Juliano de; MARCHI JÚNIOR, Wanderley. Por uma gênese do campo da sociologia do esporte: cenários e perspectivas. Movimento (Porto Alegre), v. 16, n. 2, p. 45-70, 2010. DOI: https://doi.org/10.22456/1982-8918.11159.

SOUZA JÚNIOR, Osmar Moreira de. Futebol como projeto profissional de mulheres: interpretações da busca pela legitimidade. 2013. Tese (Doutorado em Educação Física) Faculdade de Educação Física, Universidade Estadual de Campinas, Campinas, 2013.

TONDIN, Gilmar. A formação dos educadores sociais de esporte e lazer no Programa Esporte e Lazer da Cidade (PELC) em Porto Alegre. 2011. Dissertação (Mestrado em Ciência do Movimento Humano) - Escola de Educação Física, Fisioterapia e Dança, Universidade Federal do Rio Grande do Sul, Porto Alegre, 2011. Disponível em: https://lume. ufrgs.br/handle/10183/48909/. Acesso em: 25 mar. 2021.

VIALICH, Andrea Leal. O Programa Mais Educação em São José dos Pinhais: possibilidades para o esporte? 2012. Dissertação (Mestrado em Educação Física) Universidade Federal do Paraná, Curitiba, 2012. Disponível em: https://acervodigital.ufpr.br/ handle/1884/33768/. Acesso em: 25 mar. 2021.

VLASTUIN, Juliana. As "donas da quadra": leitura sociológica das unidades geracionais olímpicas do voleibol feminino no Brasil (1980-2008). 2013. Tese (Doutorado em Sociologia) - Universidade Federal do Paraná, Curitiba, 2013. Disponível em: https://www.acervodigital. ufpr.br/handle/1884/30263/. Acesso em: 25 mar. 2021.

WEBER, Max. A ética protestante e o espírito do capitalismo. São Paulo: Pioneira Thomson Learning, 2005.

WEBER, Max. Economia e sociedade. Brasília: Universidade de Brasília, 2000.

WEBER, Max. Rejeições religiosas do mundo e suas direções. In: GERTH, Hans Heinrich; WRIGHT MILLS, Charles. Ensaios de sociologia. Rio de Janeiro: Zahar, 1974. p.372.

ZAMBELLI, Túlio Mateus. Significados da natação para praticantes máster de um clube cidade de Porto Alegre: um estudo etnográfico. 2014. Dissertação (Mestrado em Ciência do Movimento Humano) - Escola de Educação Física, Fisioterapia e Dança, Universidade Federal do Rio Grande do Sul, Porto Alegre, 2014. Disponível em: https://lume.ufrgs.br/ handle/10183/114408/. Acesso em: 25 mar. 2021.

ZIONI, Fabiola. Exclusão social: noção ou conceito? Saúde e Sociedade, v. 15, n. 3, p. 1529, 2006. DOI: https://doi.org/10.1590/S0104-12902006000300003. 
Abstract: Sports has been the object of analysis in several areas of knowledge in Brazil. An approach based on social and human sciences has enabled different perspectives, exploring unique interpretative elements that broaden the understanding of this complex phenomenon. This text aims to map studies dealing with the Sociology of Sport in Brazilian graduate programs between 2011 and 2018, aiming to contribute to the systematization of the scientific production of this subfield. After the data collection of dissertations and thesis, we described the main characteristics of these productions, classifying them into sociological categories for analysis of the sports field, with football being the most hegemonically explored modality by researchers from different areas.

Keywords: Sports. Scientific production indicators. Sociology. Review.

Resumen: El deporte ha sido objeto de análisis en diversas áreas del conocimiento en Brasil. Una aproximación a partir de las ciencias sociales y humanas ha posibilitado explorar elementos interpretativos singulares que amplían la comprensión de este complejo fenómeno. Este texto tiene como objetivo mapear estudios que abordan la Sociología del Deporte en los programas de posgrado brasileños entre 2011 y 2018, buscando contribuir con la sistematización de la producción científica de ese subcampo. Después de revisar disertaciones y tesis, describimos las principales características de estas producciones, clasificándolas en categorías sociológicas para analizar el campo deportivo, siendo el fútbol la modalidad más explorada por investigadores de diferentes áreas.

Palabras clave: Deportes. Indicadores de producción científica. Sociología. Revisión. 


\section{LICENÇA DE USO}

Este é um artigo publicado em acesso aberto (Open Access) sob a licença Creative Commons Atribuição 4.0 Internacional (CC BY 4.0), que permite uso, distribuição e reprodução em qualquer meio, desde que o trabalho original seja corretamente citado. Mais informações em: https://creativecommons.org/licenses/by/4.0

\section{CONFLITO DE INTERESSES}

Os autores declararam que não existe nenhum conflito de interesses neste trabalho.

\section{CONTRIBUIÇÕES AUTORAIS}

André Marsiglia Quaranta: Conceituação; Curadoria de dados; Análise formal; Investigação; Metodologia; Visualização; Redação - rascunho original; Redação revisão e edição.

Daniel Minuzzi de Souza: Conceituação; Curadoria de dados; Análise formal; Investigação; Metodologia; Visualização; Redação - rascunho original; Redação revisão e edição.

Fernando Marinho Mezzadri: Aquisição de financiamento; Supervisão; Redação revisão e edição.

Wanderley Marchi Júnior: Conceituação; Aquisição de financiamento; Metodologia; Análise formal; Supervisão; Redação - revisão e edição.

\section{FINANCIAMENTO}

O presente trabalho foi realizado com apoio da Coordenação de Aperfeiçoamento de Pessoal de Nível Superior - Brasil (CAPES) - Código de Financiamento 001. "This study was financed in part by the Coordenação de Aperfeiçoamento de Pessoal de Nível Superior - Brasil (CAPES) - Finance Code 001"

\section{COMO REFERENCIAR}

QUARANTA, André Marsiglia; SOUZA, Daniel Minuzzi de; MEZZADRI, Fernando Marinho; MARCHI JÚNIOR, Wanderley. Interseções entre os campos esportivo e científico: a sociologia do esporte como elemento comum (2011-2018).

Movimento (Porto Alegre), v.27, p.e27078, jan./dez. 2021. Disponível em: https:// seer.ufrgs.br/Movimento/article/view/117275. Acesso em: [dia] [mês abreviado]. [ano]. DOI: https://doi.org/10.22456/1982-8918.117275

\section{RESPONSABILIDADE EDITORIAL}

Alex Branco Fraga*, Elisandro Schultz Wittizorecki, Ivone Job*, Mauro Myskiw*, Raquel da Silveira*

*Universidade Federal do Rio Grande do Sul, Escola de Educação Física, Fisioterapia e Dança, Porto Alegre, RS, Brasil. 